\title{
Depth and distance perception in the Mongolian gerbil
}

JOHN M. COLE and JEFF S. TOPPING, University of Portland, Portland, Ore. 97203

In Experiment 1 depth perception in the Mongolian gerbil was tested on a jumping stand apparatus. Results indicate that Ss do have depth perception as measured by their increasing hesitancy to jump into an open field at greater elevations. In Experiment 2 distance perception was measured in a $T$-maze while Ss were under food deprivation. Ss learned to run to either a long or a short arm for food reward with a noncorrection procedure. All Ss learned to discriminate distances of $11 \frac{1}{2}$ and 23 in. to $98 \%$ accuracy within 140 trials. When the distances were changed to 15 and 20 in. performance dropped to $75 \%$ accuracy and remained there for 100 trials. It was concluded that within limits, gerbils do have both depth and distance perception.

Occasionally, those involved in basic research find themselves faced with the prospect of a new species of animal for use in the laboratory. Generally such a species has a number of obviously advantageous characteristics (such as being immune to respiratory diseases, being docile, etc.), as well as a number of behavioral peculiarities about which little or nothing is known. These unexplored capacities may or may not make the species suitable for further consideration or may restrict the use to certain limited types of research situations. Such is the present status of the Mongolian gerbil, Meriones unguiculatus, a small desert rodent introduced in the United States in 1954 and described in detail by Nauman (1963) and Thiessen (1968).

To date, exploration of the gerbils' physical and behavioral properties has been rather limited in scope. Walters, Pearl, \& Rogers (1963) report that gerbils learn a shock-avoidance response rapidly, being somewhat better learners than albino rats. Boice, Boice, \& Dunham (1968) report that although gerbils are superior to kangaroo rats in learning a two-way avoidance response, they are inferior to mice. Nauman (1968) reports gerbils to be less thigmotactic than rats, and Thiessen (1968) found Ss to be highly territorial. Data as to a 24-h activity cycle is conflicting, with Thiessen, Lindzey, Blum, Tucker, \& Friend (1968) reporting $\mathrm{Ss}$ to be nocturnal, while Cole and Topping 1 found Ss to be diurnal. With respect to visual capacities, Thiessen et al (1968) report a marked preference for darkness in an open field as well as an apparent lack of depth perception on the visual cliff.

It was this last observation, the apparent lack of depth perception, which stimulated the following experiments. Since anecdotal observations in the Es' own lab suggested that gerbils very definitely do have depth perception (i.e., Ss do not jump off table tops 20-30 in. high, but do jump off lower surfaces after some hesitation), it was decided to first test depth perception. Since gerbils are extremely curious animals, it was possible to use a simple jumping stand

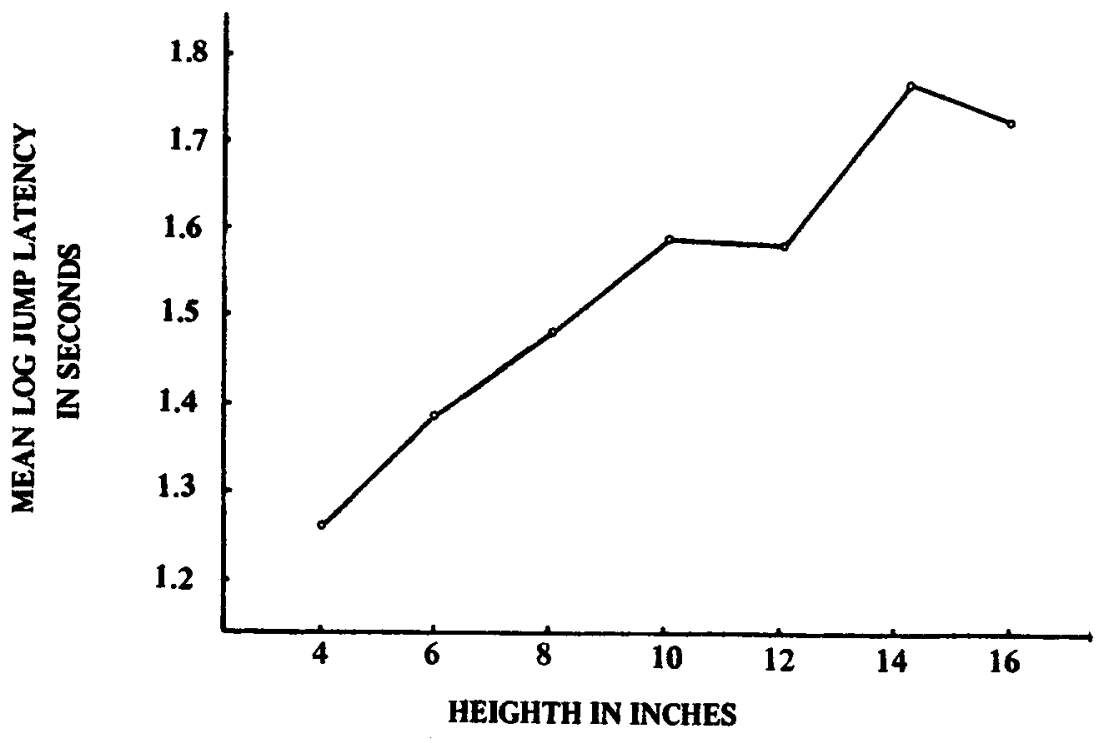

apparatus with reinforcement being access to a previously unexplored open field. It was predicted that if the Ss did have depth perception, they would be increasingly hesitant to jump at higher elevations.

EXPERIMENT 1

Subjects

The Ss were 10 Mongolian gerbils, four males and six females, ranging from 70 to 104 days old at the start of the experiment. Apparatus

A jumping stand was used which consisted of a $3 \frac{1}{2} \times 3 \frac{1}{2}$ in. wooden platform attached by an adjustable clamp to a 32-in. stainless steel rod. The rod was mounted vertically on an 8 -in. metal base, and the platform could be raised and lowered to various heights by making a simple screw adjustment. The jumping stand was placed in the middle of a circular open field having a 35-in. diam and 15-in. sides. Pine shavings ( 3 in. deep) were placed on the floor of the open field. Heights of $4,6,8,10,12,14$, and 16 in. were measured from the edge of the jumping platform to the pine shavings and marked on the rod. A 30-sec stopwatch was used for timing jump latencies.

Procedure

Each $S$ received a single daily session consisting of 28 trials on the jump stand. The seven heights were block randomized, each $S$ receiving a total of four trials at each height. The Ss were run alternately in pairs. Each trial consisted of placing the $S$ on the platform at a predetermined height and timing the latency to jump with a stopwatch. Upon jumping, Ss were allowed $30 \mathrm{sec}$ to explore the open field. The Ss were returned to individual cages between trials, and intertrial intervals varied between 35 and $155 \mathrm{sec}$. Any $\mathrm{S}$ not jumping within $2 \mathrm{~min}$ was placed in the open field for $30 \mathrm{sec}$ before being returned to the home cage.

Results and Conclusions

Jump latencies were transformed to logarithms for statistical analyses. Mean $\log$ jump latency as a function of height is presented in Fig. 1. As predicted, a definite trend toward increasing latencies with increasing heights was obtained. A 7(height) by 4 (repeated measures) ANOVA, performed on the latency data, revealed a significant effect of height $(F=3.87$, $\mathrm{df}=6 / 63, \mathrm{p}<.01)$, and trials $(F=99.88$, $\mathrm{df}=3 / 189, \mathrm{p}<.01$ ), as well as a significant Height by Trials interaction $(F=3.12$, $\mathrm{df}=18 / 189, \mathrm{p}<.01$ ). A Newman-Keuls test on overall mean latencies indicated that the following heights differed significantly $(p<.05): 4$ in. $<14$ and 16 in.; 6 in. $<$ $14 \mathrm{in.}$ Thus, while only the extreme heights

Fig. 1. Mean log jump latency in Experiment 1 as a function of platform height. 


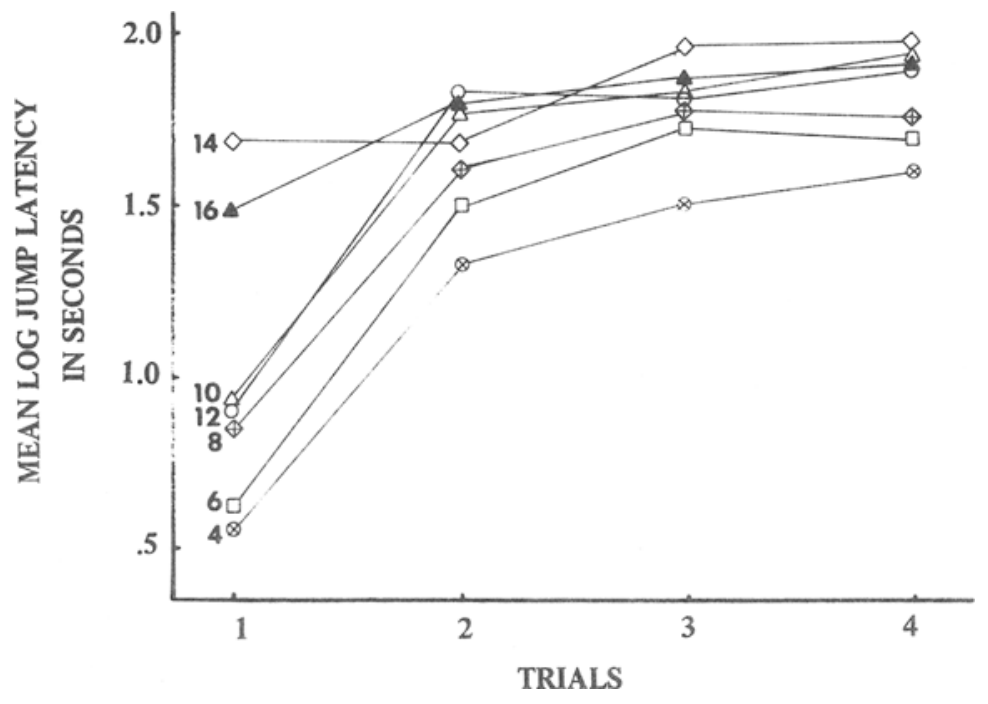

differed statistically, the overall results strongly suggest that gerbils do have depth perception to some degree.

A second Newman-Keuls test performed on trials collapsed over heights indicated that the following mean trial latencies differed significantly $(\mathrm{p}<.05)$ : Trial $1<$ Trials 2, 3, 4; Trial $2<$ Trials 3 and 4 . Thus, latencies increased with successive trials. This result would be expected if Ss satiate their curiosity fairly rapidly and are thus less motivated to explore the open field with successive trials.

The trials effect for the individual heights is presented in in Fig. 2. These data suggest that latencies increase at a sharper rate for the lower heights than for the higher heights. Thus, while Ss were initially hesitant to jump at the higher elevations, this hesitation was acquired over trials at the lower heights. These findings suggested that a more sensitive test would result from an analysis of group latencies on Trial 1 only. Results of this analysis revealed that the height effect on Trial 1 was significant $(F=9.77)$, $\mathrm{df}=6 / 63, \mathrm{p}<.01)$. A Newman-Keuls test on Trial 1 latencies indicated that the following heights differed significantly $(p<.01): 14$ in. $>4,6,8,10$, and 12 in.; 16 in. $>4,6,8,10$, and 12 in. Results of the Trial 1 analysis strongly suggest that hesitancy to jump is a function of heights, i.e., that gerbils do have depth perception. This finding is contradictory to that of Thiessen et al (1968), who used a visual cliff apparatus and found no apparent depth perception.

\section{EXPERIMENT 2}

As a logical extension of the preceding experiment, a test of distance perception was performed in which Ss were food deprived and run to either a long or a short

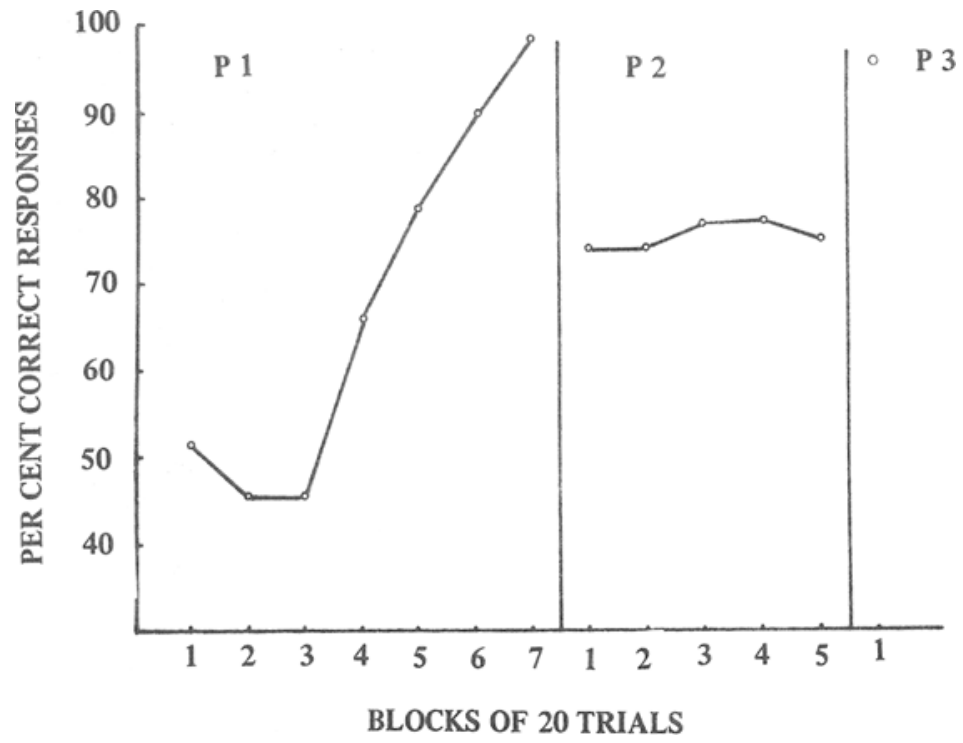

Fig. 2. Mean log jump latency in Experiment 1 as a function of trials and heights.

arm of a T-maze for food reinforcement. Distance perception, in this instance, differs from depth perception in that the former involves a horizontal plane and the latter a vertical plane. It was predicted that $S$ s would learn to discriminate between the long and short arms, thereby increasing their average rate of reinforcement from an initial chance level of $50 \%$ to a level significantly greater than chance.

Subjects

Five Mongolian gerbils, two males and three females, were selected at random from the previous experiment and were approximately $80-114$ days old at the start of the experiment.

Apparatus

A T-maze, 3 in. wide, $10 \mathrm{in.} \mathrm{high,} \mathrm{and}$ painted a flat gray throughout, was used. Two guillotine doors were located $1 \mathrm{in}$. inside each $27-\mathrm{in}$. arm and separated the arms from the 27 -in. stem. Two moveable barriers, 10 in. high and 3 in. wide, made variation in arm length possible. Located immediately in front of each barrier was a small glass food cup. The food cups were wrapped in black tape so that Ss had to traverse the length of the arm before they could discover whether reinforcement was available.

\section{Procedure}

Prior to training, Ss were food deprived to approximately $80 \%$ of their normal weight. Each $S$ then received 13 min of habituation to the unbaited maze and eight alternate free and forced-choice rewarded trials. Reinforcement on these trials and throughout the remainder of the experiment consisted of one medium-sized sunflower seed.

The Ss were randomly assigned, two to the long-arm and three to the short-arm group. Acquisition consisted of giving $\mathrm{Ss} 20$ distributed trials daily for a total of 13 days. During Phase 1 Ss chose between an $11^{1 / 2}$-in. arm and a 23-in. arm, food for a given $S$ always being associated with either the long or the short arm. Position of the correct arm was randomly ordered so that it occurred equally often on the right and left sides. A noncorrection procedure was used, guillotine doors being lowered as soon as the $S$ had made a choice and passed completely under one of the doors. Ss were allowed to consume the reinforcement on correct choice trials and were restrained for $20 \mathrm{sec}$ on incorrect choice trials before being returned to their home cages for ITIs of

Fig. 3. Per cent correct responses during all phases of Experiment 2. 
approximately $4 \mathrm{~min}$. Phase 1 lasted for 7 days or a total of 140 trials.

In Phase 2, barrier distances of 15 and $20 \mathrm{in}$. were used to provide a more difficult discrimination. Phase 2 lasted for 5 days or a total of 100 trials.

As a final test that $S$ s were still responding to distance cues, Phase 3 consisted of 1 day of 20 trials with the original discrimination distances of $11 \frac{1}{2}$ and 23 in.

Results and Conclusions

Results of Experiment 2 are presented in Fig. 3. Clearly, all Ss learned to discriminate distance in order to obtain food reinforcement. Since no reliable differences were found with respect to the long vs short arm, all Ss were combined for data analysis. By the final block of Phase 1 , Ss were making the correct choice with $98 \%$ accuracy. When the discrimination was made more difficult in Phase 2, performance immediately dropped to approximately $75 \%$ accuracy and did not improve over a 5-day period. In Phase 3, Ss were returned to the initial discrimination of Phase 1 and the result was an immediate return to $97 \%$ accuracy. From this experiment, it was concluded that gerbils do have distance perception, at least within the ranges used in the present experiment. Nearly perfect discrimination was possible when the arms differed by $11 \frac{1 / 2}{2}$ in. and $75 \%$ accuracy was maintained when the difference was only 5 in.

\section{REFERENCES}

BOICE, $R$, BOICE, C. \& DUNHAM, A. E. Role of docility in avoidance: Gerbils and kangaroo rats in a shuttlebox. Psychonomic Science, 1968, 10, 381-382.

NAUMAN, D. J. The Mongolian gerbil as an experimental animal in behavioral research. Paper read at North and South Dakota Bi-State Psychological Convention, South Dakota, 1963.

NAUMAN, D. J. Open field behavior of the Mongolian gerbil. Psychonomic Science, 1968, $10,163-164$.

THIESSEN, D. D. The roots of territorial marking in the Mongolian gerbil: A problem of species-common to pography. Behavio Research Methods \& Instrumentation, 1968, 1 , 70-76.

THIESSEN, D. D., LINDZEY, G., BLUM, S. TUCKER, A., \& FRIEND, H. Visual behavior of the Mongolian gerbil (Meriones unguiculatus). Psychonomic Science, 1968, 11, 23-24.

WALTERS, G. C., PEARL, J., \& ROGERS, J. V. The gerbil as a subject in behavioral research. Psychological Reports, 1963, 12, 315-318.

\section{NOTES}

1. Cole, J. M., \& Topping, J. S. Twenty-four hour activity cycles in the Mongolian gerbil. Unpublished manuscript, 1969.

\section{Enhanced pattern discrimination learning following unilateral damage to posterior cortex in rats}

\begin{abstract}
THOMAS J. BOLES, University of Utah and Veterans Administration Hospital, Salt Lake City, Utah 84112, and CHARLES L. SHERIDAN, University of Missouri and Veterans Administration Hospital, Kansas City, Mo. 64110
\end{abstract}

Rats with unilateral damage to the posterior cortex, including the "visual" cortex, learned a monocular pattern discrimination substantially more quickly than did an unoperated group. A unilaterally blinded group did not differ reliably from unoperated animals.

In several experiments, groups of albino rats with unilateral ablation of the "visual" cortex have acquired a monocular pattern discrimination more rapidly than unoperated or "sham" operated groups (Creel \& Sheridan, 1965; Dunsmore, Creel, $\&$ Sheridan, 1965). It is easy to account for these findings by postulating the presence of interhemispheric interference in intact animals. Indeed, there have been several studies reported in the literature which are very much in consonance with the view that across-the-midline interference occurs. Krech, Rosenzweig, \& Bennett (1960) found that unilateral lesions in the visual and somesthetic cortex of rats causes a "slight but significant" increase in cholinesterase activity in the contralateral cortex. Bingelli, Tschirgi, \& Wenzel (1963) found that unilateral tectal lesions augmented the learning of visual discriminations in pigeons. Sprague (1966) has shown that a reciprocally interfering relationship holds between the two superior colliculi in cats under some circumstances. All of these phenomena are intelligible if across-the-midline interference of symmetrical brain halves is postulated.

It would be of considerable interest if such mutual interference of the two cerebral hemispheres in rats could be shown to occur, but the evidence is only suggestive, and the replicability of these findings as well as their susceptibility to alternative interpretations need to be evaluated. It was with the latter two needs in mind that the present experiment was undertaken. Our first purpose was to replicate the previous findings of enhanced discrimination learning following unilateral ablation. Our second purpose was to evaluate a simple hypothesis which suggests itself as an alternative to the above mentioned central interference hypothesis. If an important component of the monocular discrimination task has to do with the acquisition of orientations appropriate to the unilaterally blinded condition, operated (and therefore hemianopic) rats might come to the task from an advantageous starting point.

Operated animals can presumably learn new habits of visual fixation in the home cage, whereas unoperated animals must acquire them while learning the discrimination task. The experiment reported here made possible the evaluation of this "visual fixation" hypothesis by determining whether unilateral orbital enucleation has an effect equivalent to that of unilateral striate ablation.

\section{SUBJECTS}

Twenty-one male Sprague-Dawley albino rats obtained from Simonsen Laboratories, Inc., Day Road, Gilroy, California, were used as Ss.

\section{APPARATUS}

Training was given in a Thompson-Bryant apparatus (Thompson \& Bryant, 1955), which utilized shock motivation and consisted of a start box, runway, choice point with two alternative entryways (blocked by the cue doors), and a goalbox.

\section{PROCEDURE}

From the original pool of 21 rats, seven pairs were selected haphazardly for surgery. The members of each pair were anesthetized with Nembutal ( $50 \mathrm{mg} / \mathrm{kg}$, intraperitoneal) and then one of them was chosen at random for striate ablation, the other for removal of one eye. Ablations were accomplished by subpial aspiration. Enucleations were done by introducing a forceps underneath the orb and cutting it away with scissors.

After at least 2 weeks of recovery, Ss were selected from the pool of 21 rats to be run in squads, usually of four animals. Each squad included at least one animal from each of the three treatment groups.

Subjects were pretrained to run to the goalbox, and to knock over grey cue cards which blocked the goalbox entryways. One eye was then covered with an opaque contact occluder similar to those of Schuck \& Copolla (1963), except that it covered the eye to its base, and Ss were trained to discriminate $1 / 2$-in. horizontal from $1 / 2$-in. vertical stripes which were taped to the cue doors. The correct cue was varied unsystematically across Ss. Right-left position of the correct stimulus was determined by a Gellerman series (Gellerman, 1933). Training continued until a criterion of 18 correct responses in 20 consecutive trials was met.

After completion of the experiment, the ablated rats were sacrificed by perfusion in mammalian Ringer's solution followed by $10 \%$ formalin. Their brains were removed, embedded in paraffin; and 10-micron coronal sections were taken over varying 